\title{
Anorectal malformations with sacral bony abnormalities
}

\author{
S NOUR, ${ }^{*}$ D KUMAR, $†$ AND J A S DICKSON* \\ ${ }^{*}$ Paediatric Surgical Unit and †Centre for Human Genetics, Children's Hospital, Sheffield
}

SUMMARY A range of anorectal malformations with sacral bony abnormalities was found in members from three generations of two kindreds. The anorectal anomaly was low in all but one of the patients. Partial sacral agenesis was the main bony defect in one family, and meningomyelocele and spina bifida occulta were noted in the second. The inheritance pattern in these kinships is autosomal dominant. This may be a variant of caudal regression syndrome, which seems to be aetiologically heterogeneous.

Anorectal malformations are a group of anomalies with an estimated incidence of one in 5000 live births. ${ }^{1}$ This congenital anomaly can be associated with bony defects in the sacrum. The bony defect varies from partial to complete sacral agenesis, to spina bifida occulta, or meningomyelocele. We describe subjects from two families each affected with an anorectal anomaly and a bony defect of the sacrum segregating in an autosomal dominant manner.

Documentation of these kinships is important in view of the clinical and genetic implications. We also discuss the aetiological heterogeneity of these congenital anomalies, which may be part of the caudal regression or dysplasia syndrome. ${ }^{2}$

\section{Subjects}

FAMILY A

The details of family A (fig 1) were obtained from

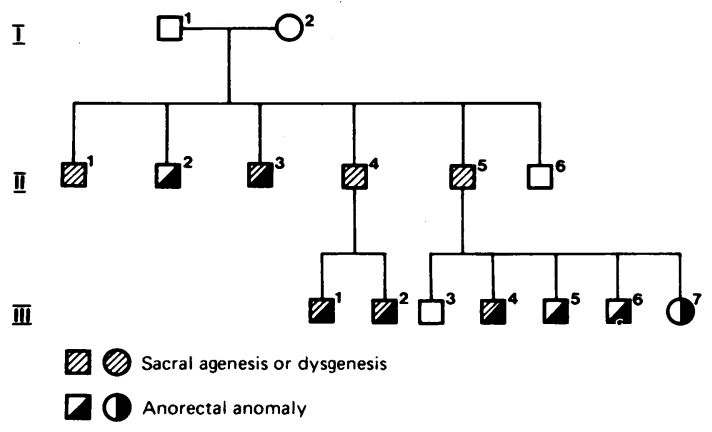

Fig 1 Pedigree of family $A$. the medical records of the paediatric surgical unit at this hospital. Two of the six brothers (II.2 and II.3) had low anorectal anomalies with partial sacral agenesis in one (II.3). Three (II.1, II.4, and II.5) had radiological evidence of partial sacral agenesis. II.1 also had left hemiparesis and scoliosis. Both children of II.4 had low anorectal anomalies and partial sacral agenesis. Four of the five children fathered by II. 5 had low anorectal anomalies (III.4? and III.7). Radiological examination showed that four children had normal sacrums (III.3, III.5, III.6, and III.7). The grandparents of these siblings did not give consent for radiological examination, but have no history of anorectal anomalies or symptoms suggestive of any bony defect.

\section{FAMILY B}

The proband III.2 (fig 2) was referred for genetic counselling because of a low anorectal anomaly and a family history of neural tube defects. She also had a bicornuate uterus, spina bifida occulta, and a duplex left kidney. Her first pregnancy (IV.1) resulted in a male infant who died 16 hours after birth of complications of a lumbosacral meningomyelocele. Her second son (IV.2) was born with a high anorectal anomaly that was treated first by formation of a colostomy and then by an anorectal pull through operation. Radiological examination showed a spina bifida occulta of the upper sacrum. The proband's father (II.4) and mother (II.3) were normal. The proband's only sibling (III.3) is in good health and has two normal, healthy children (IV.4 and IV.5). One of the father's sisters (II.7) died in early infancy from complications associated with an anorectal anomaly, and a brother (II.9) died at the 


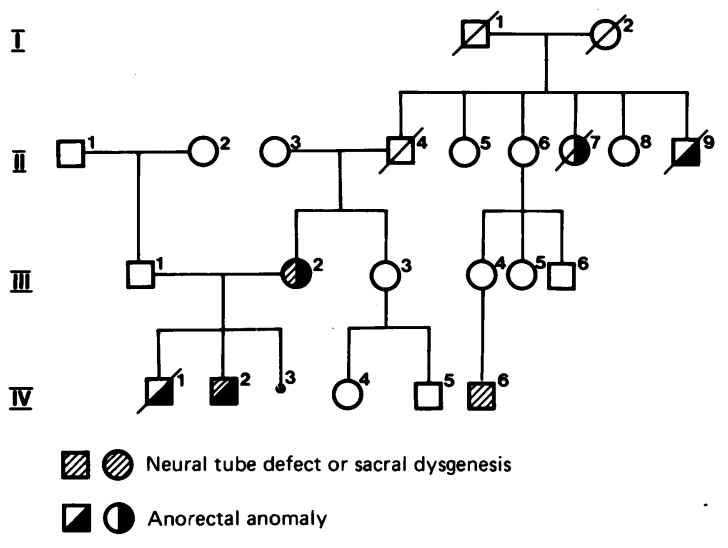

Fig 2 Pedigree of family $B$.

age of 7 hours with an open meningomyelocele. A second cousin of IV.2 (IV.6) also had a spina bifida occulta of the lower spine.

\section{Discussion}

Although congenital anorectal anomalies as a group are fairly common, there is a wide range of varieties. All the patients, except one child, in these two families had low anorectal anomalities. Partial sacral agenesis predominated in the first family, and spina bifida occulta in the second family. Meningomyelocele can be anterior and presents as a mass in the pelvic cavity. The lack of a positive family history of maternal diabetes reduces the possibility of an environmental factor for sacral agenesis or dysgenesis.

Segregation of the anorectal anomalies and the partial sacral agenesis in these two kinships is an indication of an autosomal dominant inheritance with complete penetrance and variable expression. Male to male expression excludes $\mathrm{X}$ linked inheritance. Although there are published examples that support the genetic aetiology for anorectal anomalies and sacral agenesis occurring independently, ${ }^{3}$ concurrent familial occurrence of these two anomalies is rare. Autosomal dominant inheritance has also been proposed for sacral àgenesis. ${ }^{4}$

Welch and Aterman suggested that the syndrome of caudal dysplasia should be distinguished from familial sacral agenesis. ${ }^{5}$ Fellous et al reported an association between sacral agenesis and spina bifida occulta or aperta, or both, in a five generation pedigree, suggesting an autosomal dominant inheritance. ${ }^{6}$ In the same pedigree, segregation and linkage studies using a number of genetic poly- morphisms, including the human leucocyte antigens, favoured a major dominant gene for the sacral agenesis in association with spina bifida aperta. When examined for spina bifida occulta, the evidence in favour of mendelian inheritance was less convincing. These authors believe that the major dominant gene determining the sacral agenesis is similar to the mouse ' $T$ ' locus, which is the dominant tail length determining gene located on chromosome 17 approximately $15 \mathrm{cM}$ from the $\mathrm{H} 2$ locus. (The mouse $\mathrm{H} 2$ gene complex is equivalent to the human leucocyte antigen gene complex on the short arm of chromosome 6.) In mice, unlike humans, it is not the dominant mutation ' $T$ ' but the recessive ' $t$ ' alleles that determine the length of the tail; the dominant ' $\mathrm{T}$ ' is lethal in the homozygotes. In some pedigrees of familial sacral agenesis, the inheritance pattern is autosomal recessive suggesting genetic heterogeneity. ${ }^{78}$

In searching published work we found only one report (by Aaronson in $1970^{7}$ ) who described a family with concurrent anorectal anomalies and partial sacral agenesis. Similarly, in pedigrees with anorectal anomalies segregating in an autosomal dominant pattern, we found no evidence of association with sacral agenesis, partial or complete. ${ }^{9}$

That the anorectal anomalies and sacral bony defects are aetiologically related may be explained on the basis of a defect of the caudal notochord during the first few weeks of embryogenesis. An incomplete separation may result in a low anorectal anomaly, a sacral bony defect, and a presacral mass that could be meningocele, teratoma, or duplication cyst. ${ }^{10}$ This association has been called the 'Currarino triad'. ${ }^{11}$ These varieties of anomalies can be described under the title of caudal regression syndrome.

In conclusion, the two kinships described in this paper provide strong evidence of an autosomal dominant pattern for the combined anorectal and sacral bony defects. It is important to obtain radiographs of the lumbosacral spine in all babies with anorectal anomalies. Partial sacral agenesis may explain incontinence of urine and stool in patients with low anorectal anomalies. We believe that genetic counselling is likely to offer help and advice to families with such a group of anomalies, and clinicians should be aware of the association between anorectal malformations and partial sacral agenesis and its dominant pattern of inheritance.

\footnotetext{
References

1 Parkkulainen KV. Sacrococcygeal and urological anomalies in connection with congenital malformations of anus and rectum. A preliminary report. Annales Paediatriae Fenniae (Helsinki) 1957;3:51-7.
} 
2 Jones KL. Caudal dysplasia sequence. Smith's recognizable patterns of human malformations. 4th ed. Philadelphia: WB Saunders, 1988:574-5.

${ }^{3}$ McKusick VA. Mendelian inheritance in man. 8th ed. Baltimore: Johns Hopkins University Press, 1988.

${ }^{4}$ Say B, Coldwell JG. Hereditary defect of the sacrum. Humangenetik 1975;27:231-4.

5 Welch JP, Aterman K. The syndrome of caudal dysplasia: a review, including etiologic considerations and evidence of heterogeneity. Pediatr Pathol 1984;2:313-27.

${ }^{6}$ Fellous M, Boue J, Malbrunot C, et al. A five generation family with sacral agenesis and spina bifida: possible similarities with the mouse T-locus. Am J Med Genet 1982;12:465-87.

7 Aaronson I. Anterior sacral meningocele, anal canal duplication cyst and covered anus occurring in one family. $J$ Pediatr Surg 1970;5:559-63.
${ }^{8}$ Finer NN, Bowen P. Dunbar LG. Caudal regression anomalad (sacral agenesis in siblings). Clin Genet 1978;13:353-8.

${ }^{9}$ Kaijser KA, Malstrom-Groth A. Ano-rectal abnormalities as a congenital familial incidence. Acta Paediatrica (Uppsala) 1957; 46:199-200.

10 Currarino G, Coln D, Moteler T. Triad of anorectal, sacral and presacral anomalics. AJR 1981;137:395-8.

" Kirks DR, Morten DF, Filston HC, Oakes WJ. The Currarino triad: complex of anorectal malformations, sacral bony abnormality, and presacral mass. Pediatr Radiol 1984;14:220-5.

Correspondence and requests for reprints to Mr JAS Dickson, Paediatric Surgical Unit, The Children's Hospital, Western Bank, Sheffield S10 2TH.

Accepted 23 Junc 1989 